\title{
CONCEPTS
}

\section{Implementing Wilderness Medicine Training for Undergraduate Medical Students in the UK}

\author{
Jonathan Schulz, BSc; Jake Warrington, BSc; Conal Maguire, DDS; \\ Thomas Georgi, BA; Russell Hearn, MBBS, MSc., FRCGP, FAWM, FAcadMEd, SFHEA \\ School of Population Health \& Environmental Sciences, Faculty of Life Sciences \& Medicine, King's College London, London, United Kingdom
}

\begin{abstract}
The UK General Medical Councils' approved curricula share only 3 topics with the Fellowship in the Academy of Wilderness Medicine core curriculum, suggesting an underrepresentation of wilderness medicine (WM) in medical education. We developed a 5-mo course to address the gaps between these curricula to run in parallel with the conventional curriculum. Our 71-h course is composed of lectures and practical exercises. We set out to evaluate the effectiveness of this concept and assess its suitability for use by other institutions. The course was undertaken by 18 medicine and healthcare undergraduates. Semiquantitative evaluation of the course was done using participants' self-reported WM knowledge and interest before and after the course using a Likert scale. Participants were further assessed with a WM objective structured clinical examination. Before the course, students had a lower understanding of WM (2.8/5.0) and were not confident in prehospital medicine (2.5/5.0). After the course, knowledge and confidence increased in all teaching categories, with a mean gain of 1.4/5.0 $(P<0.05)$. Students demonstrated competence in a range of WM categories by completing the WM objective structured clinical examination, with a pass rate of $82 \%$. Providing students with a WM course is effective in introducing components of the Fellowship in the Academy of Wilderness Medicine curriculum and inspiring future engagement in the field. We have developed a framework for successful implementation of WM teaching and shown that the concept may be used in other undergraduate settings.
\end{abstract}

Keywords: medical education, prehospital, emergency medicine, curriculum, teaching

\section{Introduction}

In the United Kingdom, the General Medical Council approve the curricula of 65 specialties and 32 subspecialties taught in UK medical schools. ${ }^{1}$ Of these curricula, wilderness medicine (WM) is not included as a specialty, and only 3 topics (tropical medicine, prehospital emergency medicine, and public health medicine) overlap with the core credit disciplines in the Fellowship in the Academy of Wilderness Medicine Curriculum ${ }^{2}$ (FAWM) from the

Presented at the Academy of Medical Educators' UK Clinical Teaching Fellows Forum, June 2019, Frimley, UK, and the Wilderness Medical Society 2019 Summer Conference, July 2019, Crested Butte, CO.

Corresponding author: Russell Hearn, MBBS, MSc., FRCGP, FAWM, FAcadMEd, SFHEA, School of Population Health \& Environmental Sciences, 4th Floor, Addison House, Guy's Campus, KCL, London, SE1 1UL, United Kingdom; e-mail: russell.hearn@kcl.ac.uk.

Submitted for publication June 2019.

Accepted for publication November 2019.
Wilderness Medical Society (WMS). This suggests an underrepresentation of WM in UK medical education. Since 2015, the Wilderness Medicine Society of King's College London Student Union has run a faculty-supported, FAWM-approved WMS training course that focuses on complementing the core curriculum with WM-specific lectures and workshops.

WM opportunities for medical students tend to exist as educational courses ${ }^{3,4}$ or medical electives. ${ }^{5}$ However, these are generally costly ${ }^{6}$ and do not run in conjunction with undergraduate teaching or timetables, which acts as a barrier to student engagement. ${ }^{6,7}$ This article will provide a model for running an extended extracurricular WM course for UK undergraduate university students. Using the feedback from participants, we examine the effectiveness of WM teaching, and how the course can be improved in future editions. We also evaluate whether there is a need for basic clinical medical knowledge to enable students to achieve the relevant learning outcomes of the course. 

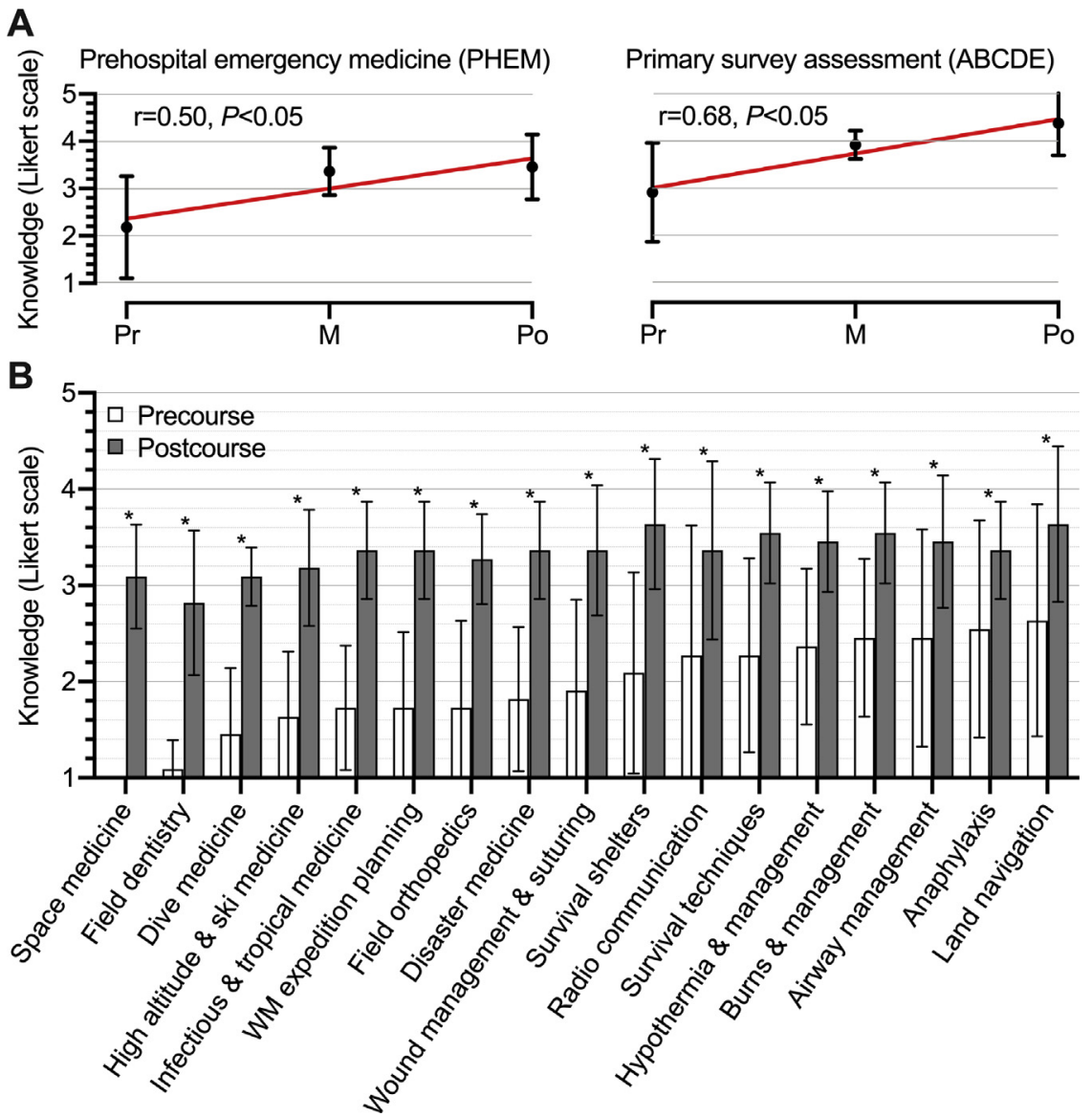

Figure 1. Change in student self-reported knowledge of teaching categories. Semiquantitative knowledge by students using a Likert scale. A: Key teaching categories that recurred throughout the course. Pr indicates precourse; M, midcourse; Po, postcourse. Significance indicated as Spearman's rank correlation coefficient. B: Teaching categories on the course arranged by precourse knowledge (increasing left to right). WM indicates wilderness medicine. Disaster medicine includes disasters, bioterrorism, and humanitarian response. Infectious and tropical medicine includes infectious diseases, insects and snakes, malaria, vector-borne diseases, vector control, and sexually transmitted infections. *Statistically significant results with $P<0.05$.

\section{COURSE DESIGN}

The 5-mo WM course ran in parallel with the conventional undergraduate curriculum. It comprised $71 \mathrm{~h}$ of lectures, workshops, and practical exercises, including 2 weekends in the field. Campus-based sessions were taught in clinical classrooms and lecture theatres. The course was designed to run during university-protected times for student extracurricular activities, such as varsity sport programs, educational interest groups, and medical research opportunities. Although this meant there was competition for student time, it allowed for a structured organization of the course.

A committee of 4 facilitators from the Wilderness Medicine Society of King's College London Student Union acted as course organizers. Their roles included administrative tasks, constructing the framework of the course, and assisting teaching sessions. The curriculum was mapped to 50 credit-scoring activities from the WMS FAWM curriculum, ${ }^{2}$ with preference given to core activities. Credit-scoring activities were grouped into 19 teaching categories for analysis (Figure 1). A proposed program was sent to the WMS in advance of the course for approval as an eligible activity toward the FAWM. The proposal included the title, format, description, and objective of each teaching activity, in addition to the duration of the activity and detailed credentials of the presenters. The course was taught by interdisciplinary experts, both internal and external to our faculty, who volunteered their time to teach on the course. These included graduates with a FAWM, physicians, surgeons, dentists, nurses, military personnel, and humanitarian aid experts. Based on our proposal, the WMS agreed the course could be accredited for FAWM credit.

Applicants were admitted on a first-come, first-served basis for students able to demonstrate an interest in 


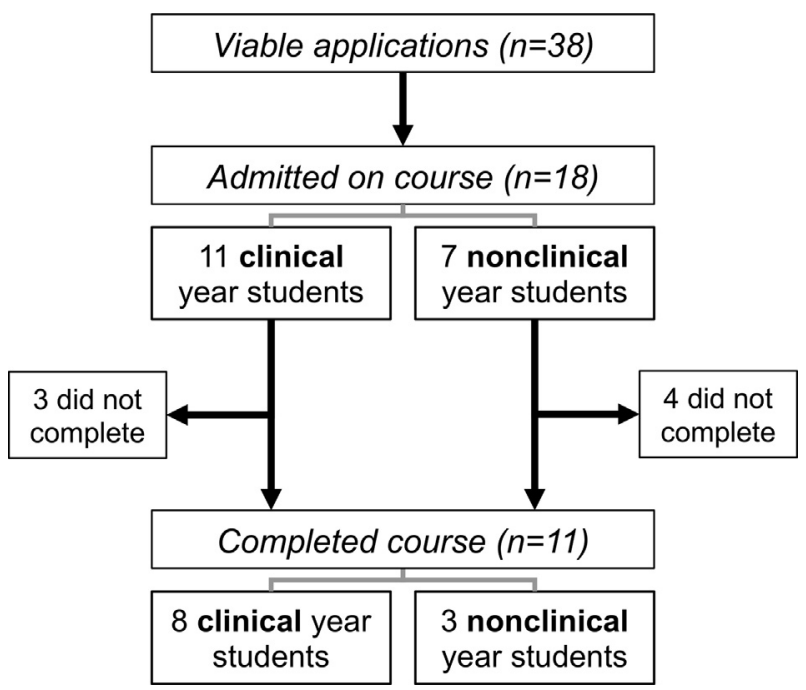

Figure 2. Course cohort. Thirty-eight viable applications received, and 18 students admitted on the course: 11 completed the course and 7 did not complete the course to a satisfactory standard. Completion rate: $61 \%$; clinical years completion rate, $72 \%$; nonclinical year completion rate, $43 \%$.

pursuing WM. All students were required to be current medical, nursing, or medical science undergraduates. The course was restricted to a maximum of 18 students, which was believed to provide an optimal teaching environment for both invited teachers and students and in both classroom settings and practical sessions. To complete the course, students had to attend $\geq 80 \%$ sessions and a WM objective structured clinical examination (WMOSCE).

Students were asked to evaluate the course and their own WM knowledge at the start, at the midpoint, and after completion. All responses were anonymous. Only students who completed the course were included in our analysis (Figure 2). The King's College London research ethics office exempts service evaluations from requiring internal ethical clearance and approval where there is no change to the standard service being delivered. Although ethical approval is not required, the work adheres to basic ethical principles set out by the research ethics office.

Semiquantitative student WM interest, understanding, and knowledge of teaching categories were collected before and after the course via participants' self-reported responses using Likert scales ${ }^{8}$ (Table 1). Key teaching categories, which recurred throughout the course, included prehospital emergency medicine (PHEM) and primary survey patient assessment (ABCDE).

Feedback to evaluate the course was also obtained. Semiquantitative course rating across 9 course rating categories was collected midcourse and postcourse using a Likert scale $^{8}$ (Tables 1 and 2). Qualitative analysis was undertaken using thematic analysis of free-text trainer and student feedback across 4 domains: enjoyment, improvement, structure, and effectiveness.

A 7-station WM-OSCE, which included 6 practical stations and 1 written station, assessed knowledge at the end of the course. The assessment was modelled on the King's College London examination boards' medical school examination. ${ }^{9}$ Candidates were graded within each of the following domains (where applicable): clinical examination, clinical reasoning, history taking, practical skills, clinical communication skills, patient score, and patient safety. Scores were given as good, satisfactory, inadequate, or not done. Students were required to achieve an average score of good or satisfactory to pass each station. To pass the WM-OSCE, students were required to pass $\geq 5$ of 7 stations and gain a mean overall satisfactory mark across all 7 stations.

\section{STATISTICAL METHODS}

Statistical analysis was performed in Statistical Package for Social Sciences (SPSS 24.0) software (SPSS Inc., Chicago, IL). Normality of data was tested with the Shapiro-Wilk test. Continuous variables were expressed as mean \pm standard deviation (SD). Paired variables were compared using paired samples $t$ test (normally distributed) or exact Wilcoxon signed-rank test (not normally distributed). Univariate correlations were performed by using Pearson correlation coefficient (normally distributed) or Spearman rank correlation coefficient (not normally distributed). A $P$ value of less than 0.05 was used as the cut-off point to be determined a statistically significant result.

\section{COURSE EVALUATION}

The course was undertaken by 18 undergraduate students (38 viable applications received): 11 students in their clinical years and 7 students in their nonclinical years. Clinical students included medical and nursing students in their clinical years. Eleven students (clinical years, $n=8$; nonclinical years, $n=3$ ) completed the course (completion rate: $61 \%$; clinical years completion rate: $72 \%$; nonclinical years completion rate: $43 \%$ ) and were included in our analysis (Figure 2). The 39\% who did not complete the course attended less than $25 \%$ of sessions after the first month of teaching.

\section{COURSE IMPACT ON WM INTEREST AND KNOWLEDGE}

Students agreed they were interested in a career in WM (4.0/5.0, $\mathrm{SD}=0.6)$ before the course but disagreed that they understood what this career would involve (2.8/5.0, 
Table 1. Course analysis categories

\begin{tabular}{|c|c|c|}
\hline \multicolumn{2}{|c|}{ Course analysis categories } & \multirow{2}{*}{$\begin{array}{l}\text { WMS curriculum module code } \\
\text { - }\end{array}$} \\
\hline IU & I am interested in a career in $\mathrm{WM}^{*}, \mathrm{a}, \mathrm{c}$ & \\
\hline & I understand what a career in WM involves ${ }^{*}, \mathrm{a}, \mathrm{c}$ & - \\
\hline & I have basic knowledge of PHEM $^{*}, a, c$ & - \\
\hline & I am confident in performing basic PHEM $^{*}, \mathrm{a}, \mathrm{c}$ & - \\
\hline \multirow[t]{19}{*}{$\mathrm{K}$} & Airway management ${ }^{\wedge}, \mathrm{a}, \mathrm{c}$ & $12-017-5$ \\
\hline & Anaphylaxis^,a,c & 09-013-1 \\
\hline & Burns \& management ${ }^{\wedge}, \mathrm{a}, \mathrm{c}$ & $12-014-1 ; 09-003-1$ \\
\hline & Disaster medicine ${ }^{\wedge}, \mathrm{a}, \mathrm{c}$ & $11-001-1 ; 11-003-1 ; 12-022-1$ \\
\hline & Dive medicine ${ }^{\wedge}, \mathrm{a}, \mathrm{c}$ & 01-001-1; 01-002-1 \\
\hline & Field dentistry ${ }^{\wedge}, \mathrm{a}, \mathrm{c}$ & 04-001-1 \\
\hline & Field orthopedics ${ }^{\wedge}, \mathrm{a}, \mathrm{c}$ & $10-002-1 ; 12-008-1 ; 12-011-2 ; 12-021-2 ; 12-027-5 ; 12-033-2$ \\
\hline & High altitude \& ski medicine ${ }^{\wedge, \mathrm{a}, \mathrm{c}}$ & $03-001-1 ; 03-002-1 ; 06-002 ; 09-028$ \\
\hline & Hypothermia \& management ${ }^{\wedge}, \mathrm{a}, \mathrm{c}$ & 09-019-1 \\
\hline & Infectious \& tropical medicine $\mathrm{e}^{\wedge, \mathrm{a}, \mathrm{c}}$ & 02-002-1; 02-004-1; 02-035-1; 08-002-1; 09-006-1 \\
\hline & Land navigation ${ }^{\wedge}, \mathrm{a}, \mathrm{c}$ & $05-015-2 ; 06-001-1$ \\
\hline & PHEM $^{\wedge}, \mathrm{a}, \mathrm{b}, \mathrm{c}$ & 12-001-1; 12-002-1; 06-008-1; 12-011-2; 11-014 \\
\hline & Primary survey assessment $(\mathrm{ABCDE})^{\wedge, a, b, c}$ & $12-002-1$ \\
\hline & Radio communication ${ }^{\wedge}, \mathrm{c}$ & 06-001-1 \\
\hline & Space medicine ${ }^{\wedge, a, c}$ & $09-012-1$ \\
\hline & Survival techniques ${ }^{\wedge}, \mathrm{a}, \mathrm{c}$ & $\begin{array}{l}05-001-1 ; 05-003-1 ; 05-004-1 ; 05-009-1 ; 05-010-2 ; 05-013-1 ; \\
08-005-1 ; 05-016\end{array}$ \\
\hline & Survival shelters^ ${ }^{\wedge}, \mathrm{c}$ & $05-011$ \\
\hline & WM expedition planning ${ }^{\wedge}, \mathrm{a}, \mathrm{c}$ & 02-008-1; 02-010-1; 05-026-1 \\
\hline & Wound management \& suturing ${ }^{\wedge}, \mathrm{a}, \mathrm{c}$ & $09-007-1 ; 10-001-1 ; 10-002-1 ; 12-032-5$ \\
\hline \multirow[t]{10}{*}{$\mathrm{CR}$} & Knowledge ${ }^{\dagger, b, c}$ & - \\
\hline & Visual material $^{\dagger, \mathrm{b}, \mathrm{c}}$ & - \\
\hline & Relevance $^{\dagger, b, c}$ & - \\
\hline & Enthusiasm $^{\dagger, b, c}$ & - \\
\hline & Interactivity ${ }^{\dagger, b, c}$ & - \\
\hline & Structure ${ }^{\dagger, \mathrm{b}, \mathrm{c}}$ & - \\
\hline & Teaching pace ${ }^{\dagger, b, c}$ & - \\
\hline & Training officers ${ }^{\dagger, b, c}$ & - \\
\hline & Overall ${ }^{\dagger, \mathrm{b}, \mathrm{c}}$ & - \\
\hline & I would recommend this course to a colleague ${ }^{*}, \mathrm{~b}, \mathrm{c}$ & - \\
\hline
\end{tabular}

$\mathrm{IU}=$ interest and understanding of wilderness medicine; $\mathrm{K}=$ knowledge of teaching categories; $\mathrm{CR}=$ course rating; WMS $=$ Wilderness Medical Society; $\mathrm{WM}=$ wilderness medicine; PHEM = prehospital emergency medicine.

WMS credit-scoring activitie ${ }^{2}$ were grouped into teaching categories for course analysis. Disaster medicine includes disasters, bioterrorism, and humanitarian response. Infectious \& tropical medicine includes infectious diseases, insects and snakes, malaria, vector borne diseases, vector control, and STIs. Semi-quantitative analyses were completed using participants' self-reported scores on 3 Likert scales: * $1=$ 'strongly disagree', $2=$ 'disagree', $3=$ 'neutral', $4=$ 'agree', $5=$ 'strongly agree'; 1 = 'none', $2=$ 'poor', $3=$ 'good', $4=$ 'very good', $5=$ 'excellent'; $\dagger 1=$ 'poor', $2=$ 'average', $3=$ 'good', $4=$ 'very good', 5 = 'excellent'.

Responses were recorded: ${ }^{a}$ precourse, ${ }^{b}$ midcourse, and/or ${ }^{c}$ postcourse.

$\mathrm{SD}=1.3)$. After the course, students agreed or strongly agreed they were interested in a career in WM (4.3/5.0, $\mathrm{SD}=0.6$; nonsignificant increase, $P=0.38$ ) and agreed or strongly agreed they understood what this career would involve (4.5/5.0, $\mathrm{SD}=0.7$; significant increase, $P<0.05)$.

Students neither agreed nor disagreed that they had basic knowledge of PHEM (3.0/5.0, SD=1.4) before the course and disagreed that they were confident in performing basic PHEM (2.5/5.0, $\mathrm{SD}=1.4)$. After the course, students agreed or strongly agreed they had basic knowledge of
PHEM (4.4/5.0, $\mathrm{SD}=0.5$; significant increase, $P<0.05)$ and agreed or strongly agreed they were confident in performing basic PHEM (4.2/5.0, $\mathrm{SD}=0.4$; significant increase, $P<0.05$ ).

We evaluated knowledge of all teaching categories. Student self-reported knowledge increased across all teaching categories $(P<0.05)$ after the course, with a mean gain of $+1.4 / 5.0$, ranging from most knowledge gained in space medicine $(+2.1 / 5.0, P<0.05)$ to least knowledge gained in anaphylaxis $(+0.8 / 5.0, P<0.05)$. Full evaluation 
Table 2. Course rating

\begin{tabular}{lll}
\hline Course rating categories & \multicolumn{2}{l}{ Course rating } \\
\cline { 2 - 3 } & Midcourse & Postcourse \\
\hline Knowledge & $4.3 \pm 0.9$ & $4.4 \pm 0.8$ \\
Visual material & $4.3 \pm 0.8$ & $4.3 \pm 0.8$ \\
Relevance & $4.4 \pm 0.7$ & $4.5 \pm 0.7$ \\
Enthusiasm & $4.7 \pm 0.5$ & $4.7 \pm 0.5$ \\
Interactivity & $4.3 \pm 0.8$ & $4.6 \pm 0.8$ \\
Structure & $4.3 \pm 0.8$ & $4.3 \pm 0.8$ \\
Teaching pace & $4.1 \pm 0.9$ & $4.4 \pm 0.8$ \\
Course organizers & $4.8 \pm 0.4$ & $4.7 \pm 0.6$ \\
Overall & $4.5 \pm 0.5$ & $4.5 \pm 0.7$ \\
\hline
\end{tabular}

Semiquantitative course rating by students using a Likert scale: $1=$ "poor," $2=$ "average," 3="good," 4="very good," 5="excellent." Valued displayed as mean $\pm \mathrm{SD}$.

is available in Figure 1. PHEM and ABCDE knowledge increased continuously throughout the course $(\mathrm{r}=0.50$, $P<0.05 ; \mathrm{r}=0.68, P<0.05$, respectively).

Nine students passed the WM-OSCE (clinical years, $\mathrm{n}=8$; nonclinical years, $\mathrm{n}=1$; pass rate: $82 \%$; clinical years pass rate: $100 \%$; nonclinical years pass rate: $33 \%$ ). Two nonclinical years students did not pass the WM-OSCE; although both satisfied the criteria of passing $\geq 5$ of 7 stations, they did not gain a satisfactory overall mark.

\section{COURSE FEEDBACK}

Semiquantitative course rating analysis recorded mean scores across all categories as "very good" or "excellent" $(\geq 4.0 / 5.0)$ both midcourse and postcourse (Table 2). All students agreed or strongly agreed they would recommend the course to a colleague, both midcourse and postcourse.

A qualitative thematic analysis of trainer and student free-text comments was conducted. Emergent themes were coded and cross-referenced. In addition to generally positive comments, there were specific highlights or themes relevant to improving ongoing provision with selected quotes, discussed in the following subsections.

\section{CURRICULUM DESIGN}

"Very effective, a good combination of theory lectures and the chance to practice and consolidate the skills that we have learnt."

Participants enjoyed the balance of theory and practical work, which students thought was integral to WM. Students found that the near-peer teaching sessions provided an approachable and safe learning environment due to the sociocognitive congruence of facilitators and curriculum planners.

\section{EXPERTISE OF TRAINERS}

"Enjoyed the different speakers who came in to talk about their specific field as all seem quite established and made it very interesting."

Learners found the mix of facilitators and speakers gave a broad background to the subject and also allowed them to learn from experts in their field. Speakers also provided strong role-modelling for WM careers.

\section{LEVEL OF LEARNERS}

"Maybe split the course into [2] groups based on knowledge/skill level then more in depth knowledge and teaching (would be possible) for higher years."

Some students believed the mix of senior and junior medical students meant content may have been unapproachable for some and at too low a level for others. This would triangulate with performance in the WMOSCE, in which more senior medical students seemed to be able to achieve the learning outcomes of the program more readily.

\section{VOCATION AND RELEVANCE}

"The material has really resounded with me and has impacted my career choices."

Student respondents found the course inspirational and reaffirmed their aspirations to pursue a career in WM. Participants commented on how well WM interlinked with and supported the core medical curriculum and encouraged them to learn more about emergency and acute medicine.

\section{Discussion}

Medical school is a time when students identify interests within medicine that they may wish to pursue ${ }^{10}$; however, a learning need for WM is currently not being met by the UK undergraduate curriculum. Our course was oversubscribed, and our cohort demonstrated significant interest in WM before and after the course. Although students had a high interest, they were unaware of how to advance in the field and take advantage of the opportunities available. Undergraduate WM courses allow students to develop their understanding of a career in WM. ${ }^{6}$ Where other student-organized WM events have occurred, they have been successful and participants have shown improved levels of comfort in $\mathrm{WM}^{7}{ }^{7}$ Similarly, this article demonstrates a framework for the successful implementation of an extended extracurricular WM course for undergraduate students in the United Kingdom. It provides an accessible model that can be implemented with faculty and facility support under the 
guidance of a governing body. University societies are able to take advantage of their unique position within the undergraduate education system to create such a course.

Our course showed participant enjoyment and applicable knowledge gains, as demonstrated by the semiquantitative analysis and WM-OSCE results. Student self-reported knowledge of all teaching categories and of important key teaching categories (PHEM and $\mathrm{ABCDE}^{11}$ ) increased throughout the course. Our analysis showed that most knowledge was gained in teaching categories such as altitude and dive medicine, which have little representation in the undergraduate medical curriculum, whereas less knowledge was gained in teaching categories such as anaphylaxis and burns, which are covered in the undergraduate medical curriculum. Consideration should therefore be given to the time allocated to the teaching of modules that overlap with the core medical curriculum. Maximal gain in knowledge across the entire range of subjects could be achieved by focusing more time on WM modules previously unfamiliar to students. Students stated the course was well structured and effective and that they would recommend it to a colleague. In particular, the range of topics and speakers and the interactive exercises were highlights. Similar shorter WM courses have also been successful for US university students in delivering knowledge and understanding of WM. ${ }^{12,13}$

Careful consideration must be taken while setting the minimum standards for admission onto a WM course. After completion of the course, a low pass rate was noted, and it was clear that those with clinical experience in medicine performed better than their nonclinical colleagues. This is evidenced by the performance in the WM-OSCE and corresponds to findings of other courses. ${ }^{14} \mathrm{We}$ suggest that this is because students in their clinical years are relatively well practiced in the assessment of an unwell patient. This acts as a good baseline knowledge standard on which to teach applied WM knowledge. If the course were to teach baseline knowledge in addition to applied WM knowledge, it could undermine the objective of the course and therefore the quality. ${ }^{14} \mathrm{WM}$ courses taught to first-year US medical students reported the need for a follow-up course to focus on more advanced teaching. ${ }^{15}$ This prompted a suggestion to revise the admission process for future courses to give preference to students in their clinical years despite the high WM-OSCE pass rate demonstrating competency across the range of WM topics covered. Although some WM courses have required applicants to attend a selection center, ${ }^{16}$ this is likely beyond the capability of student WM societies.

Unfortunately, $39 \%$ of participants did not complete the course. The highest attrition rate was recorded at the end of the first month, when students who did not complete the course stopped regularly attending. In cases for which we were able to ask participants their reasons for dropping out, they reported that the commitment required for the course was too much, especially when the course takes place in an undergraduate's spare time and competes against other extracurricular interests. Of those who did not complete the course, $57 \%$ were preclinical students who believed the course was too advanced. This suggests that in future recruiting sessions, the time commitment and content of the course must be clearly stated so that applicants are aware of expectations. The rate of participant attrition was higher than expected. Future courses may have a higher initial course size to account for this potential dropout rate.

When evaluating student feedback, it is important to consider whether a participant's enjoyment influenced answers. Since previous WM studies have suggested enjoyment levels may influence the reported usefulness of a course ${ }^{17}$ care must be taken when selecting the tools used to evaluate sessions. ${ }^{18}$ Evaluation tools such as the Dundee Ready Education Environment Measure may be more suitable to evaluate teaching in this setting. ${ }^{19}$ Formal evaluation beyond a WM-OSCE could be achieved through the undertaking of a professional qualification, such as the Medicine in Remote Area course, as some WM courses have done, ${ }^{16}$ or from the external speakers and trainers who deliver the course. Having participants teach other students would allow for self-reflection and self-appraisal of their abilities. ${ }^{20}$

The results from this course and the lack of WM exposure in the current UK curriculum suggest it is pertinent to discuss with faculty and staff if there is a possibility of formally including WM in the undergraduate medical curriculum in the United Kingdom. Using our results, it seems that this would work best as a didactic session for preclinical students as an introduction to WM and as a mixed skills session for clinical students during their emergency medicine rotation, where patient assessment and triage skills are relatable to hospital and wilderness environments.

We found a clear division between clinical and preclinical student completion rates and assessment results. Consideration must be given to whether the course could be expanded into 2 courses, targeted to clinical and preclinical undergraduate students. This could result in a more successful course in which the separate groups have higher gains, higher enjoyment levels, and greater improvements in WM knowledge in their distinct tiered learning outcomes. Since practical sessions had high student enjoyment levels, such courses would allow for better tailored practical sessions where the need for didactic teaching could be reduced. 


\section{LIMITATIONS}

The attrition rate of participants was greater than expected: $39 \%$ of students did not complete the course. Although this attrition did not reduce the quality of the course, it meant available places were unoccupied. This also resulted in a loss of statistical power to comment on gains of knowledge. Having recognized the reasons why participants failed to complete the course, it is important that in future courses attempts be made to understand motivations for waning engagement and to promote motivation of engagement and learning. Participation as a major component of the course assessment criteria has been cited as an effective example of a tool to improve engagement. ${ }^{14}$ Changing the admission to a merit-based system may also provide spaces for the most interested students, who are more likely to complete the course. Reducing the drop-out rate would allow more students the opportunity to complete the course. Increasing the capacity of the course would also allow more students to participate; however, this would not address the underlying problem and may be counterproductive because it would jeopardize the teaching environment and undermine the effectiveness of small-group problem-based learning. ${ }^{21}$

Students suggested that improvements could be made by increasing the number of practical and interactive exercises. Although such sessions are time and cost intensive, they are effective $^{14,22}$ and enjoyable. Teaching methods could also be improved, with literature suggesting implementation of techniques such as the jigsaw method that have been successfully deployed in other WM courses. ${ }^{23}$ Securing presenters for practical sessions is a potential limitation due to the lack of faculty protected teaching time and therefore the presenters must volunteer their free time. Many presenters were contacted but unable to teach due to these constraints.

A limitation to the design being universally applicable is its heavy reliance on the use of resources, such as teaching facilities and medical equipment, provided by the university. This means that although this concept could be applied to other university society- or interest group-led programs, it would be difficult to transpose the model onto courses outside of this environment.

\section{Conclusions}

We have demonstrated the successful implementation of a WM course alongside a UK conventional undergraduate curriculum and achieved increased levels of WM knowledge and interest. This course represents a framework upon which a university society-led WM course can be built to teach WM to undergraduate students in the United
Kingdom. Such a course can provide students with elements of WM that are not traditionally taught in the undergraduate curriculum.

Acknowledgments: Charlotte Greene (president), Constance Osborne (vice president), and all the 2017 to 2018 committee members from Wilderness Medicine Society of King's College London Student Union greatly contributed to and assisted in the running of the course.

Author Contributions: Study concept and design (JS, JW, CM, TG); acquisition of the data (JS, JW, CM, TG); analysis of the data (JS); drafting of the manuscript (JS, JW, CM, TG, RH); critical revision of the manuscript (JS, JW, CM, TG, RH).

Financial/Material Support: King's College London Faculty of Life Sciences \& Medicine supports the course through provision of rooms, equipment, and faculty support. The King's College London Students' Union Development Fund supports the course through a grant equivalent to $\$ 800$ USD. This money is for provision of the course; it is not related to and does not provide the research/evaluation of the course as presented in this manuscript.

Disclosure: None.

\section{References}

1. General Medical Council. Royal college curricula. Available at: www.gmc-uk.org/education/standards-guidance-andcurricula/curricula. Accessed April 11, 2019.

2. Wilderness Medical Society. Fellowship in the academy of wilderness medicine. Available at: www.wms.org/fawm. Accessed April 11, 2019.

3. Auerbach P, Lemery J. Wilderness medicine. Medical Student Survival Guide. 2001:1156.

4. McIntosh SE, Leemon D, Visitacion J, Schimelpfenig T, Fosnocht D. Medical incidents and evacuations on wilderness expeditions. Wilderness Environ Med. 2007;18(4):298-304.

5. Schrading WA, Battaglioli N, Drew J, McClure SF. Core content for wilderness medicine training: development of a wilderness medicine track within an emergency medicine residency. Wilderness Environ Med. 2018;29(1):78-84.

6. Fielding CM. Introducing medical students to wilderness medicine. Wilderness Environ Med. 2011;22(1):91-3.

7. Lareau SA, Robinson PE, Wentworth SS, McGinnis HD. Impact of a student-organized conference on wilderness medicine education. Wilderness Environ Med. 2014;25(1):120-1.

8. Likert R. A technique for the measurement of attitudes. Arch Psychol. 1932;22(140):55.

9. Vince T. OSCE Guide 2018/19: A One-Stop Guide for Students and Faculty. King's College London: GKT School of Medical Education; 2018.

10. Ibrahim M, Fanshawe A, Patel V, Goswami K, Chilvers G, Ting M, et al. What factors influence British medical students career intentions? Med Teach. 2014;36(12):1064-72.

11. Donelan S. Student electives in wilderness medicine: curriculum guidelines: An introduction. Wilderness Environ Med. 2014;25(4):472-3.

12. Joy KE, Reno EM, Kaplan B, Miner T, Lemery JM. Bridging the gap: introducing undergraduate students to wilderness and emergency medicine. Wilderness Environ Med. 2015;26(4):e2. 
13. Watson SC, Sterner SE, Bush JS, Bourne CL. Development and implementation of a standardized wilderness medicine curriculum (AWLS) for fourth year medical students. Wilderness Environ Med. 2015;26(1):97.

14. Macias DJ, Rogers K, Alcock J. Development of a wilderness and travel medicine rotation in an academic setting. Wilderness Environ Med. 2004;15(2):136-45.

15. Cordes DH, Rea DF, Gerhauser R. Wilderness medicine: a clinical introduction for medical students. $J$ Wilderness Med. 1992:3(4):367-71.

16. Hardern R. Wilderness medicine: a teacher's perspective. Clin Teach. 2009;6(3):143-6.

17. McGraw D, Gluckman SJ. The perceived benefits of a medical school course in wilderness medicine. Wilderness Environ Med. 2005;16(2):106-10.

18. Donelan S. Evaluating and improving your classes. Wilderness Environ Med. 2001;12(2):134-8.
19. Roff S, McAleer S, Harden RM, Al-Qahtani M, Ahmed AU, Deza H, et al. Development and validation of the Dundee Ready Education Environment Measure (DREEM). Med Teach. 1997;19(4):295-9.

20. Andrews L, Biles B, Taylor I. Effective and transferable teaching methods from wilderness medicine: the students' perspective. Clin Teach. 2009;6(3):147-51.

21. Springer L, Stanne ME, Donovan SS. Effects of small-group learning on undergraduates in science, mathematics, engineering, and technology: a meta-analysis. Rev Educ Res. 1999;69(1):21-51.

22. Lareau SA, Kyzer BD, Hawkins SC, McGinnis HD. Advanced wilderness life support education using high-technology patient simulation. Wilderness Environ Med. 2010;21(2):166-170 e2.

23. Mazoyer P, Hardern RD. Lessons learned on a wilderness medicine "teaching weekend". Wilderness Environ Med. 2011;22(3):277-80. 